\title{
Modified Numerical Simulation Model of Blood Flow in Bend
}

\author{
X Liu, X Zhou, X Hao, X Sang
}

\begin{abstract}
The numerical simulation model of blood flow in bend is studied in this paper. The curvature modification is conducted for the blood flow model in bend to obtain the modified blood flow model in bend. The modified model is verified by $U$ tube. By comparing the simulation results with the experimental results obtained by measuring the flow data in U tube, it was found that the modified blood flow model in bend can effectively improve the prediction accuracy of blood flow data affected by the curvature effect.
\end{abstract}

Keywords: Blood flow, model, numerical simulation

\section{Modelo de Simulación Numérica Modificado del Flujo Sanguíneo en Curva}

\author{
X Liu, X Zhou, X Hao, X Sang
}

\begin{abstract}
RESUMEN
Este trabajo constituye un estudio del modelo de simulación numérica del flujo sanguíneo en curva. La modificación de la curvatura se lleva a cabo para el modelo de flujo de sangre en la curva para obtener el modelo de flujo de sangre modificado en curva. El modelo modificado se verifica mediante un tubo en U. Comparando los resultados de la simulación con los resultados experimentales obtenidos mediante la medición de los datos de flujo en el tubo en $U$, se observa que el modelo de flujo sanguíneo modificado en curva puede mejorar con eficacia la exactitud de la predicción de los datos del flujo sanguíneo afectados por el efecto de la curvatura.
\end{abstract}

Palabras claves: Flujo sanguíneo, modelo, simulación numérica

West Indian Med J 2015; 64 (5): 495

\section{INTRODUCTION}

According to the reports of the World Health Organization, cardiovascular disease has become the number one threat to human health. In order to better understand the physiological and pathological behaviour of cardiovascular diseases, the indepth study of arterial blood flow has become very important in haemodynamics. Among many cardiovascular diseases, arterial thrombosis is a common vascular disease that adversely affects human health. Thrombotic disease occurs mostly at the position near the bending and bifurcation of blood vessels. Its formation mechanism and reason is complex, and current research mainly focusses on the treatment and care of clinical cases. Clinical observations indicate that the pathogenesis and disease development of arterial disease is closely related to haemodynamic characteristics [such as flow field distribution,

From: School of Mechatronic Engineering and Automation, Shanghai University, Shanghai 200072, China.

Correspondence: X Liu, School of Mechatronic Engineering and Automation, Shanghai University, 149 Yanchang Road, Zhabei District, Shanghai 200072, China. E-mail: xiaoguangvisa@126.com wall shear stress, etc] (1-5). With the continuous development of computational fluid dynamics (CFD), the numerical simulation technology based on CFD has gained increasingly wide application in the study of haemodynamics, becoming an important research tool. Human blood vessels have complex geometrical structure, but Coppola and Caro (6) proved that the helical tube model, to a certain extent, could be adopted to obtain the blood flow parameters similar to those in human blood vessels. By using the helical tube model to simulate blood flow, combined with the methods of CFD and theories of haemodynamics, and considering the impact of two-phase blood flow and non-Newtonian feature, the dynamic analysis of blood flow can be conducted. Based on the CFD method, current studies mainly focus on the effect of blood flow on the formation of thrombus from the aspects of initial velocity of blood flow entrance, curvature radius of bending, vessel diameter and blood viscosity, while there are relatively fewer studies of the blood flow model in blood vessels. Normally, the body's blood circulation belongs to laminar flow. However, when the blood flow rate is accelerating to a certain ex- 
tent, the laminar flow will be destroyed. As a result, the blood flow direction of each particle no longer remains the same, and whirlpool appears. The current flow state is very complex during this time. A variety of secondary flow and whirlpool flow makes it more difficult to predict the state of blood flow field by numerical simulation. In order to accurately simulate the internal flow field of turbulent blood flow, it is critical to select the appropriate turbulence model and conduct corresponding modifications for it to improve the accuracy of numerical prediction.

\section{Curvature effect}

The flow that has a curvature effect is common in the actual turbulence, $e g$ bend flow, wing's turbulent flow, etc. At present, in the numerical computation of turbulence in bend blood flow, the numerical simulation of turbulent flow containing a curvature is a challenging task in the application of turbulence model. Durbin and Reif (7) studied the curvature effect on flow and conducted the analysis through comparing the curvature with the rotation. For a convex side, the speed increases in the radial direction. Then the convex side plays the role of reducing the amount of turbulent energy in shear flow. For a concave side, the turbulent energy of shear flow that flows through a concave side increases.
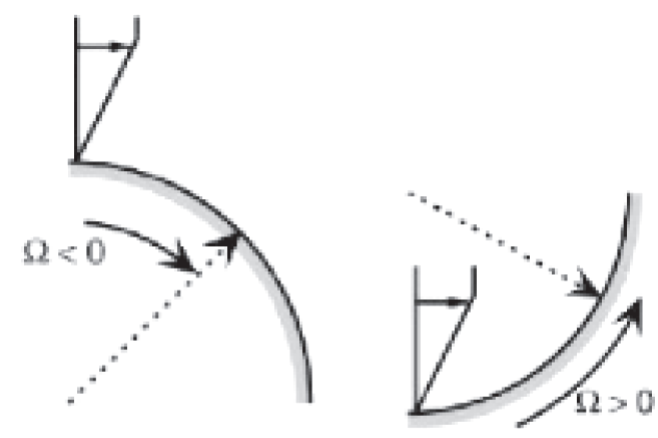

\section{Convex side Concave side}

Fig. 1: Schematic diagram of the analogy between curvature and rotation.

\section{Renormalization group k-epsilon (RNG k- $\varepsilon$ ) model}

There will be some distortion for the standard k- $\varepsilon$ model when used in strong whirlpool flow or curved-wall flow. In order to improve the disadvantages of the standard k- $\varepsilon$ model, Yakhot and Orzag made some modifications (8). The small scale effect is reflected by the viscosity after large-scale movement and modification. The rotation and whirlpool flow in average flow is considered by modifying the turbulence viscosity and the RNG k- $\varepsilon$ model is established. In the RNG k- $\varepsilon$ model, the turbulence viscosity $\mu_{t}$ can be expressed as a function of $k$ and $\varepsilon$, namely:

$$
\mu_{t}=\rho C_{\mu} \frac{k^{2}}{\varepsilon}
$$

Where the transport equations of turbulence kinetic energy $k$ and turbulence dissipation rate $\varepsilon$ are:

$$
\begin{aligned}
\frac{\partial(\rho k)}{\partial t}+\frac{\partial\left(\rho k u_{i}\right)}{\partial x_{i}} & =\frac{\partial}{\partial x_{j}}\left[\alpha_{k} \mu_{e f f} \frac{\partial k}{\partial x_{j}}\right] \\
\frac{\partial(\rho \varepsilon)}{\partial t}+\frac{\partial\left(\rho \varepsilon u_{i}\right)}{\partial x_{i}} & =\frac{\partial}{\partial x_{j}}\left[\alpha_{\varepsilon} \mu_{e f f} \frac{\partial \varepsilon}{\partial x_{j}}\right] \\
+ & \frac{G_{1 \varepsilon}^{*} \varepsilon}{k} G_{k}-\mathrm{C}_{2 \varepsilon} \rho \frac{\varepsilon^{2}}{k}
\end{aligned}
$$

Where $G_{k}$ is the production term of turbulence kinetic energy and the model's constants are

$$
C_{\mu}=0.0845, \alpha_{k}=\alpha_{\varepsilon}=1.39, C_{1 \varepsilon}=1.42, C_{2 \varepsilon}=1.68, \eta_{0}=4.377, \beta=0.012 .
$$

\section{Modified RNG k- $\varepsilon$ model}

In order to improve the computation accuracy of eddy viscosity model in solving the flow problem with curvature effect, many scholars have proposed different empirical modification methods. Spalart and Shur proposed the experienced modification method based on the material derivative of strain rate (9-11) where model modification was done through multiplying the production term in the S-A model with a modification function $f_{r}$. Analysis of examples verified that the modified model has higher accuracy in solving the problem of the flowing curvature effect. The curvature modification method proposed by Spalart and Shur has a strong versatility and applicability. Many researchers have applied the above method to SST k- $\varepsilon$ model and have received good results.

For the modification of RNG k- $\varepsilon$ model, we can draw from the method of Spalart and Shur proposed $(12,13)$ to modify the production term $G_{k}$ in the transport equation of turbulence kinetic energy $k$ and turbulence dissipation rate $\varepsilon$. The transport equations of turbulence kinetic energy $k$ and turbulence dissipation rate $\varepsilon$ after the curvature modification are:

$$
\begin{array}{r}
\frac{\partial(\rho k)}{\partial t}+\frac{\partial\left(\rho k u_{i}\right)}{\partial x_{i}}=\frac{\partial}{\partial x_{j}}\left[\alpha_{k} \mu_{e f f} \frac{\partial k}{\partial x_{j}}\right] \\
+G_{k} f_{r}+\rho \varepsilon \\
\frac{\partial(\rho \varepsilon)}{\partial t}+\frac{\partial\left(\rho \varepsilon u_{i}\right)}{\partial x_{i}}=\frac{\partial}{\partial x_{j}}\left[\alpha_{\varepsilon} \mu_{e f f} \frac{\partial \varepsilon}{\partial x_{j}}\right] \\
+\frac{G_{1 \varepsilon}^{*} \varepsilon}{k} G_{k} f_{r}-C_{2 \varepsilon} \rho \frac{\varepsilon^{2}}{k}
\end{array}
$$

Where modification coefficient $f_{r}$ is:

$$
f_{r}=\max \left[0,1+C_{\text {scale }}\left(f_{r}-1\right)\right]
$$


Where $C_{\text {scale }}=0.1$.

The expression of argument $\overline{f_{r}}$ is:

$\overline{f_{r}}=\max \left[\min \left(f_{r 1}, 1.25\right), 0.0\right]$

Where the constant in modified RNG $\mathrm{k}-\varepsilon$ model adopts the same value with the constant in RNG $\mathrm{k}-\varepsilon$ model and the curvature modification factor uses Equation [6].

\section{Verification by examples}

$\mathrm{U}$ bend flow is a flow problem with strong curvature effect. The structure of $U$ bend is shown in Fig. 2, where width $H$ is $40 \mathrm{~mm}$, bend's inner radius is $20 \mathrm{~mm}$, bend's outer radius is 55 $\mathrm{mm}$, and select $\mathrm{H}$ as the feature length.

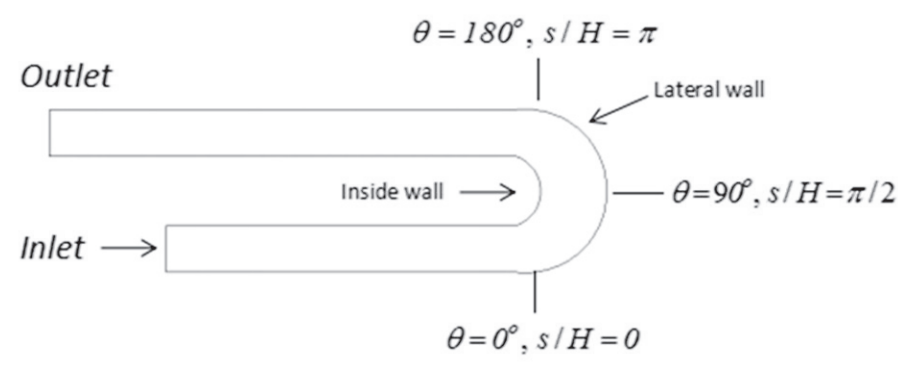

Fig. 2: Graph of U tube.

For the boundary conditions, velocity boundary is adopted for entrance. According to the experimental conditions of Monson et al (14), we need to make sure that the number of $\mathrm{Re}$ with entrance width $\mathrm{H}$ as the feature length is $1 \times$ $10^{6}$, that turbulence intensity at the entrance is $0.1 \%$ and eddy viscosity ratio is 5 . The exit adopts free outflow and the solid wall adopts no-slip boundary condition (15).

\section{RESULT ANALYSIS}

In Fig. 2, entrance's average velocity $U_{m}$ is adopted as a reference value in the selected $U$ tube in order to conduct dimensionless treatment for the velocity of each point; Y-axis takes the width $\mathrm{H}$ as the base. Then the medial wall is $\mathrm{Y} / \mathrm{H}=0$ and the lateral wall is $\mathrm{Y} / \mathrm{H}=1$.

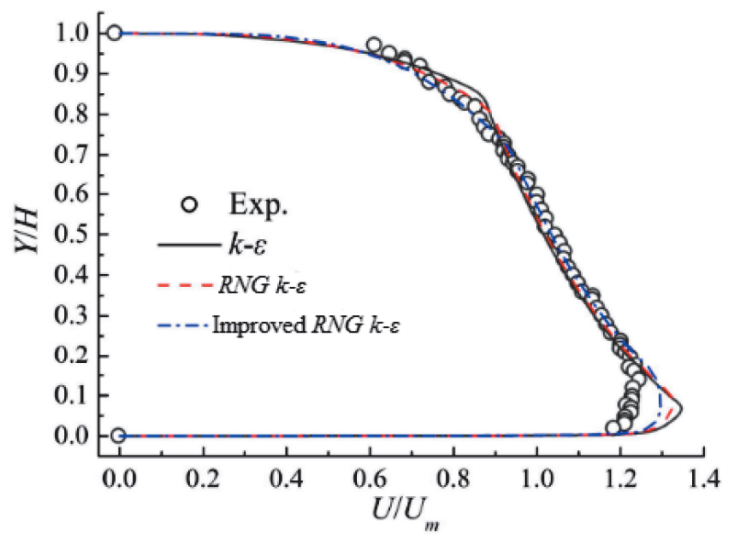

Fig. 3: Angle of 0 degree.

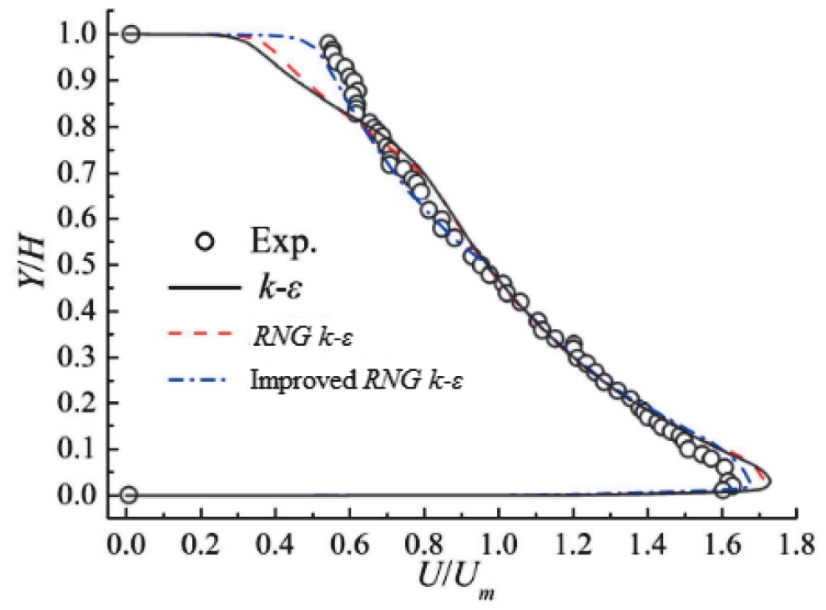

Fig. 4: Angle of 90 degrees.

At the tube's entrance, the angle is 0 degree, as shown in Fig. 3. As the fluid flow of this location is less affected by the curvature effect, the differences of velocity distribution calculated by each model is not large, all close to the velocity distribution obtained by experimental measurement; at the tube's middle, the angle is 90 degrees, as shown in Fig. 4. The RNG $\mathrm{k}-\varepsilon$ model after curvature modification is in better agreement with the velocity distribution by experimental measurement than the standard k- $\varepsilon$ model and RNG k- $\varepsilon$ model.

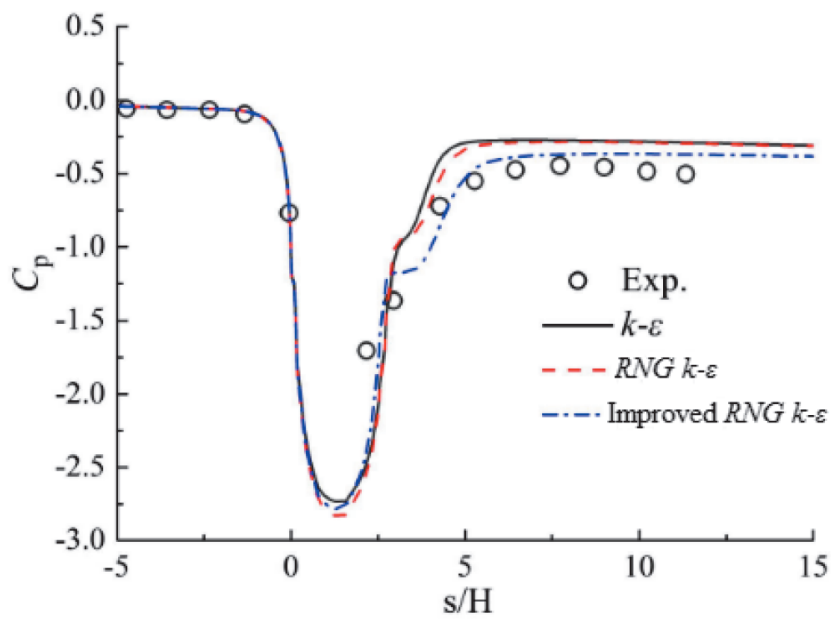

Fig. 5: Medial wall.

Figures 5 and 6 are the pressure distributions of medial and lateral walls, respectively, where the pressure coefficient is $C_{p}$ and the entrance's average velocity is $U_{m}$. We can see from Figs. 5 and 6 that the distribution of pressure coefficient $C_{p}$ of medial and lateral walls predicted by each model is in good agreement with the experimental results at the entrance's straight segment of $U$ tube; and from the bend's entrance to the U tube's exit, the distribution of pressure coefficient $C_{p}$ of medial and lateral walls predicted by the modified RNG k- $\varepsilon$ model is in the best agreement with the experimental results 


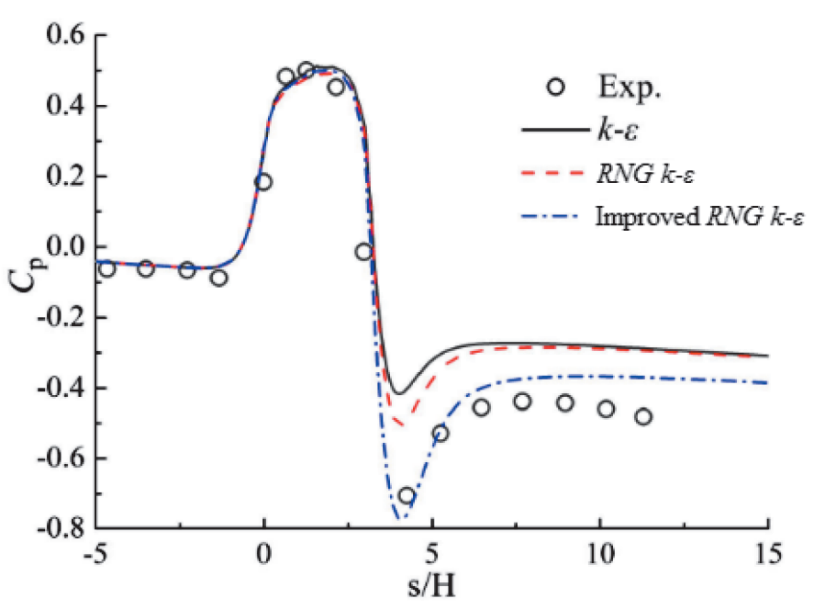

Fig. 6: Lateral wall.

when compared with the other two models. By comparing the simulation results with the experimental results of U tube's internal flow, it is found that the standard k- $\varepsilon$ model and the RNG $k-\varepsilon$ model have less accuracy for calculating the flow in bending segment, while the modified RNG k- $\varepsilon$ model can effectively improve the flow's numerical prediction accuracy affected by wall curvature effect.

\section{CONCLUSION}

A computational fluid dynamics method is adopted to study the numerical simulation model of blood flow in bend. Curvature modification is conducted for the model of blood flow in bend to obtain the modified model of blood flow in bend. $U$ bend with strong curvature effect is used to conduct verification experiments. The modified RNG k- $\varepsilon$ model can effectively improve the flow's numerical prediction accuracy affected by the wall curvature effect, laying the foundation for further research on blood flow in bend.

\section{REFERENCES}

1. Liu GT, Wang XJ, Ai BQ, Liu L-G. The advance of blood flow in complicated artery. Chinese J Med Phys 2003; 03: 168-71.

2. Badimon L, Vilahur G, Padro T. Nutraceuticals and atherosclerosis: human trials. Cardiovasc Ther 2010; 28: 202.

3. Mitchell LE, Long J, Garbarini J, Paluru P, Goldmuntz E. Variants of folate metabolism genes and risk of left-sided cardiac defects. Birth Defects Res A Clin Mol Teratol 2010; 88: 48-53.

4. Musunuru K, Lettre G, Young T, Farlow DN, Pirruccello JP, Ejebe KG et al; NHLBI Candidate Gene Association Resource. Candidate gene association resource (CARe): design, methods, and proof of concept. Circ Cardiovasc Genet 2010; 3: 267-75.

5. Shinkai H. Cholesteryl ester transfer-protein modulator and inhibitors and their potential for the treatment of cardiovascular diseases. Vasc Health Risk Manag 2012; 8: 323-31.

6. Coppola G, Caro C. Oxygen mass transfer in a model three-dimensional artery. J R Soc Interface 2008; 5: 1067-75.

7. Durbin PA, Pettersson Reif BA. Statistical theory and modeling for turbulent flows. Chichester: John Wiley \& Sons; 2011.

8. Yakhot V, Orszag SA. Renormalization group analysis of turbulence. I. Basic theory. J Sci Comput 1986; 1: 3-11.

9. Launder BE, Priddin CH, Sharma BI. The calculation of turbulent boundary layers on spinning and curved surfaces. J Fluids Eng 1977; 99: 231-9.

10. Park SW, Chung MK. Curvature dependent two-equation model for prediction of turbulent recirculating flows. AIAA J 1989; 27: 340-4.

11. Spalart PR, Shur M. On the sensitization of turbulence models to rotation and curvature. Aerosp Sci Technol 1997; 1: 297-302.

12. Shur ML, Strelets MK, Travin AK, Spalart PR. Turbulence modeling in rotating and curved channels: assessing the Spalart-Shur correction. AIAA J 2000; 38: 784-92.

13. Zhang Q, Yang Y. A new simpler rotation/curvature correction method for Spalart-Allmaras turbulence model. Chinese J Aeronaut 2013; 26: 326-33.

14. Monson DJ, Seegmiller HL, Mcconnaughey PK. Comparison of experiment with calculations using curvature-corrected zero and two equation turbulence models for a two-dimensional. Presented at: Fluid Dynamics, $21^{\text {st }}$ Plasma Dynamics and Lasers Conference; Seattle, WA; June 18-20, 1990 .

15. Mani M, Ladd JA, Bower WW. Rotation and curvature correction assessment for one-and two-equation turbulence models. J Aircraft 2004; 41: $268-73$. 